\title{
Combined Therapy for Mandibular Prognathism: Sagittal Split Osteotomy with Excision of Tongue
}

\author{
Mehtap Karamese*, Osman Akdağ, Muhammed Nebil Selimoglu, Malik Abacı, \\ Ahmet Akatekin, Zekeriya Tosun \\ Department of Plastic Reconstructive and Aesthetic Surgery, Selcuk University, Konya, Turkey \\ Email: "mehtapef@yahoo.com
}

Received 30 June 2014; revised 25 July 2014; accepted 21 August 2014

Copyright (C) 2014 by authors and Scientific Research Publishing Inc.

This work is licensed under the Creative Commons Attribution International License (CC BY).

http://creativecommons.org/licenses/by/4.0/

(c) (i) Open Access

\begin{abstract}
In the evaluation of the beauty and functional integrity of the lower face, the oral cavity, teeth, mandible, maxilla, and the size and position of the tongue are important. The tongue locates forward and is larger than normal in prognathism, in which the jaw protrudes from the skull. It is not clear whether an enlarged tongue causes the open bite, protrusion or dental arch misalignment, or is a result of them. Here, we report two patients with mandibular prognathism and relative macroglossia, which were treated by mandibular setback surgery using a bilateral sagittal split osteotomy (BSSO) and excision of the tongue. This procedure achieved aesthetic improvement of the face and dentition.
\end{abstract}

\section{Keywords}

Relative Macroglossia, Mandibular Prognathism, Mandibular Setback Surgery, Bilateral Sagittal Split Osteotomy

\section{Introduction}

Mandibular setback surgery using a bilateral sagittal split osteotomy (BSSO) has routinely been used as an orthognathic surgical procedure for mandibular prognathism [1]. Macroglossia is defined as tongue enlargement due to muscle hypertrophy, tumor or an endocrine disturbance. Pseudo macroglossia, or relative macroglossia, is defined as the tongue being normal in size, but appearing large due to its anatomical reciprocation [2]. The tongue locates forward and is larger than normal in prognathism, and this macroglossia may cause problems such as

*Corresponding author.

How to cite this paper: Karamese, M., Akdağ, O., Selimoglu, M.N., Abacı, M., Akatekin, A. and Tosun, Z. (2014) Combined Therapy for Mandibular Prognathism: Sagittal Split Osteotomy with Excision of Tongue. Modern Plastic Surgery, 4, 53-57. http://dx.doi.org/10.4236/mps.2014.44010 
Class III malocclusion and an open bite [3]. It is not clear whether the macroglossia arises from mandibular prognathism or dental arch misalignment. It must be kept in mind that the tongue will be relatively larger after a mandibular setback operation.

Unfortunately, tongue size cannot be determined using objective criteria [4], and evaluating macroglossia is necessary when planning treatments for prognathism. Relative macroglossia affects post-treatment stability and pushes the mandible forward. Discrepancies between the size of the tongue and oral cavity after setback operations can be estimated based on the clinical appearance of the tongue, and excision of the tongue is sometimes performed as part of the total treatment for Class III skeletal problems and anterior open bites. These cases have a rather large tongue size for the space available, resulting in speech problems, tooth flaring, and abnormal skeletal growth [5].

In this article, we aimed to share the planning, technique, and results of combined orthodontic treatment with orthognathic surgery and excision of the tongue. These were simultaneously performed in two adult patients with mandibular prognathism and relative macroglossia.

\section{Clinical Report}

\subsection{Case 1}

This patient was an 18-year-old man who presented with chief complaints of lack of incisal contact, mandibular protrusion, and mastication problems. His facial profile was concave, with chin protrusion and a long lower facial height. The patient had an angle Class III malocclusion with a total cross bite ( $-9.5 \mathrm{~mm}$ of overjet), and excessive open bite ( $-2.5 \mathrm{~mm}$ of overbite). Although his tongue was rather large, he showed no difficulty in speech production of the word team. According to the surgical plan, it was decided to setback the mandible $8.4 \mathrm{~mm}$ on the right side and $8.0 \mathrm{~mm}$ on the left side, with excision of the tongue (Figure 1).

BSSO was used to retract the mandible, and after controlling this, the condyle was properly positioned and the osteotomy fixed with bicortical compressive screws. Intermaxillary fixation was maintained for 3 weeks, using elastics with a Class III component and occlusal splint. In postoperative orthodontic treatment, 0.017 " × 0.025" NiTi and 0.017" $\times 0.025 "$ SS arches were inserted in both arches and the occlusion was detailed using elastics. Postoperative orthodontic treatment lasted for 9 months.

\subsection{Case 2}

This patient was a 21-year-old woman with mandibular protrusion, a concave facial appearance, an angle Class III malocclusion, with a relatively large tongue. According to the surgical plan, it was decided to set back the mandible $7.9 \mathrm{~mm}$ on right side and $7.0 \mathrm{~mm}$ on left side, with an excision of the tongue. BSSO was used to retract the mandible, and after controlling this, the condyle was properly positioned and the osteotomy was fixed with bicortical compressive screws. Intermaxillary fixation was maintained for 3 weeks, using elastics with a Class III component and occlusal splint. In postoperative orthodontic treatment, 0.017 " $\times 0.025$ " NiTi and $0.017 " \times 0.025$ " SS arches were inserted in both arches and the occlusion was detailed using elastics. Postoperative orthodontic treatment lasted for 9 months (Figure 2).

\subsection{Tongue Resection}

The tongue was taken out of the mouth using a hook and 4/0 silk suture. Excision marking was made based on the teeth marks on the tongue. Excision of tongue was done with a scalpel and electro cautery (Figure 3). Continuous stiches with $4 / 0$ vicryl were used for closing the raw surface of the tongue.

\section{Results}

The patients' maxillary midlines were lined up with the mandibular and facial midlines. The overjet and overbite were minimal. The posterior occlusions were finished with Class I canine and molar relationships in both of the segments. The inadequate maxillary tooth display before treatment was increased.

Side effects of tongue excision, such as bleeding, tongue edema, and paralysis, were not seen in either of these two patients. Motor function of the tongue and the function of the hypoglossal nerve and salivary duct were not impaired. The patients stated that there was no loss of the sense of taste. Speech and masticatory problems were not seen. 


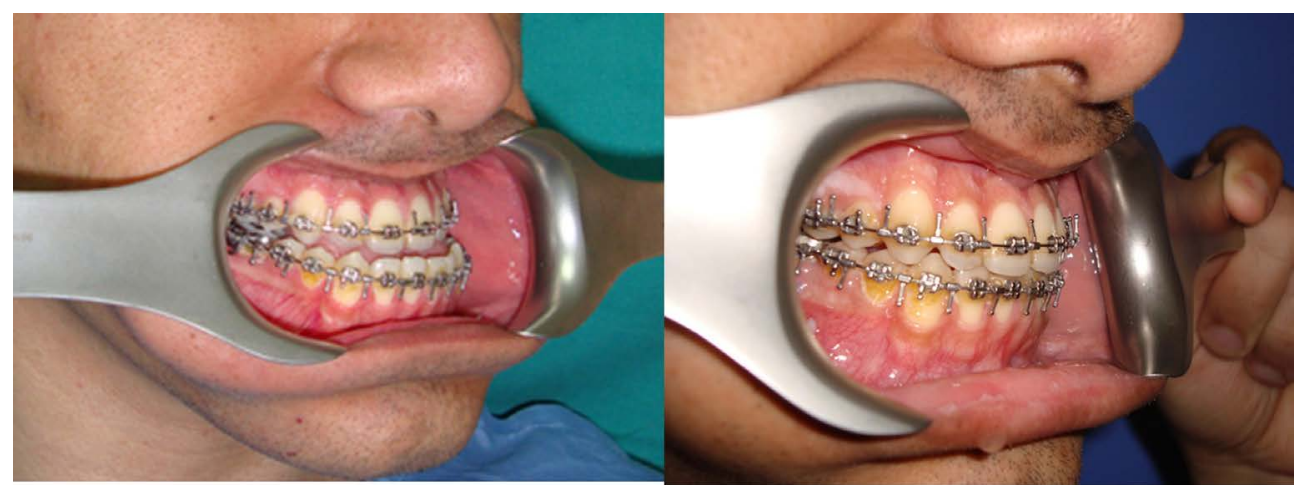

Figure 1. A 18 years old man with prognathism. Preoperative and postoperative views.

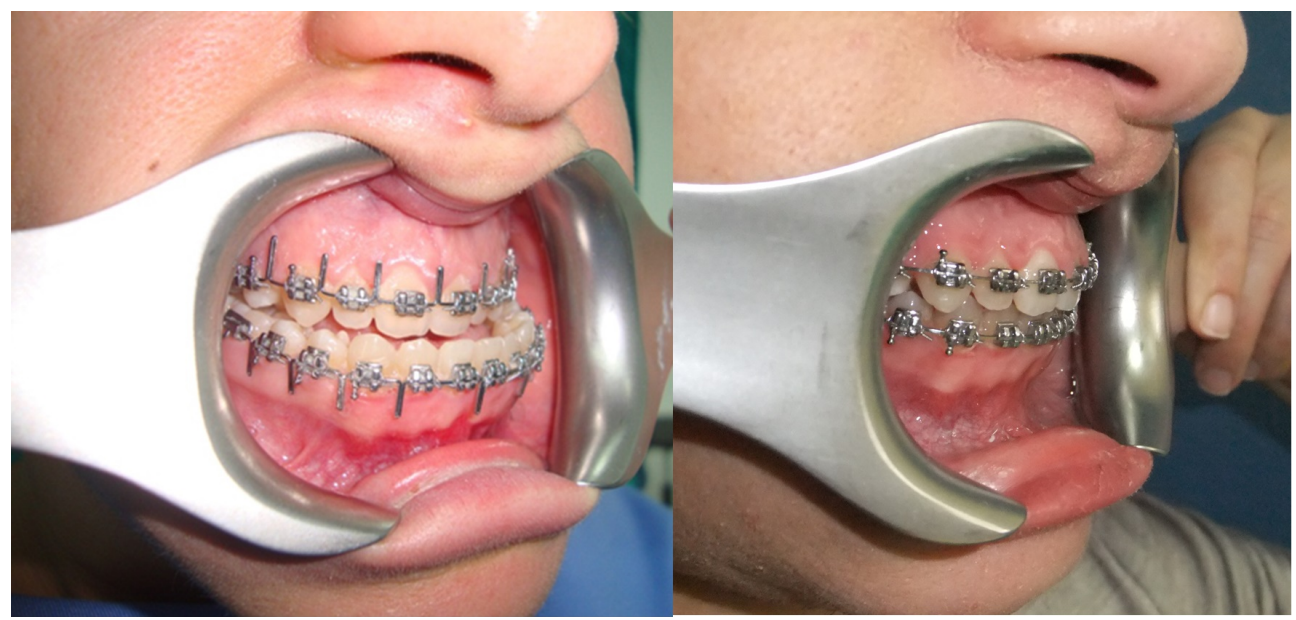

Figure 2. A 21-year-old woman with mandibular prognathism. Preoperative and postoperative views.

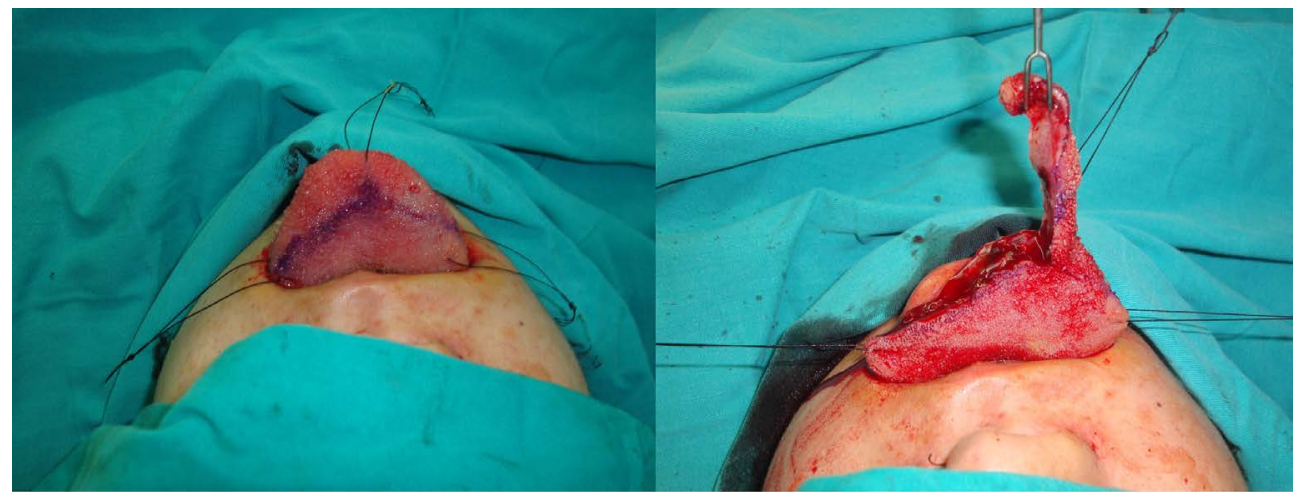

Figure 3. Excision marking of tongue is shown in left. Excision of tongue is shown in right.

\section{Discussion}

These two patients with prognathism were successfully treated by combined orthodontic treatment with orthognathic surgery, while the excision of the tongue was simultaneously performed. Neither tongue function was deteriorated, nor was a relapse of mandibular prognathism seen.

Prognathism is a challenging problem for orthodontic treatment, and requires surgery to correct. Treatment becomes even more difficult in the presence of relative macroglossia. The pushing force of the tongue may propel the mandible forward and cause a relapse of prognathism. Excision of the tongue may decrease the probability of relapse and improve stability [6]. 


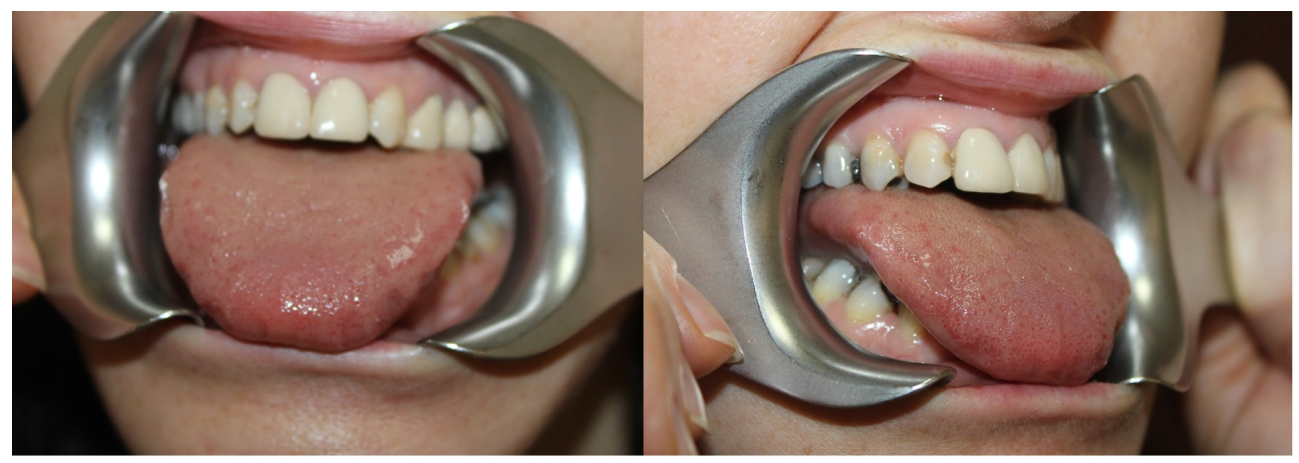

Figure 4. Teeth marks on the tongue at rest.

The necessity of tongue resection is evaluated with an observation of the size of the tongue, teeth marks on the tongue at rest, and angulation of the incisor teeth, mandibular and occlusal planes [2] (Figure 4). After the setback operation of the mandible, the tongue will be larger than it was previously due to the backward positioning of the mandible.

In these cases, we performed an excision of the tongue after fixation of the mandible. The excision of the tongue can be performed a long time before the orthognathic surgery to prevent the edema and respiratory problems which may occur when both surgeries are performed at the same time [7]. We excised the side parts of the tongue which made contact with the teeth (Figure 3 and Figure 4). The keyhole-shaped technique can be used for the excision of the tongue, but we believe that this type of excision creates a greater risk of edema, bleeding, and dysfunction of the tongue [8]. We advocate a conservative approach for the excision of the tongue, when combined with BSSO. This procedure does not cause complications and can be performed during orthognathic surgery. The patients could speak and eat within 2 days after surgery. The function of the tongue was restored 7 days after surgery, and these patients did not experience changes in the sense of taste.

Tanaka et al. used the keyhole-shaped technique and reported changes in taste sensation due to changes in the filiform papillae. The authors also advocated speech therapy to restore this ability in their patients [8].

Some authors have advocated tongue reduction in the Le Fort I surgical procedure or in the correction of open bite malocclusion to avoid relapse [7]-[10]. According to Schwenzer et al., in the presence of malocclusion caused macroglossia, the incidence of relapse is lower when the reduction of the tongue size is combined with orthodontic treatment [11].

Some patients with malocclusion have teeth marks on the tongue at rest, depending on the degree of improper closing (Figure 4). Multiple traumas created by the teeth hurt the tongue, cause desensitization and even malignant disease. The excision of the tongue may relieve injuries to the tongue.

\section{Conclusion}

The excision of the tongue may be an auxiliary component of treatment for patients with malocclusion caused by an enlarged tongue, because it contributes to the stability of the occlusion after surgical treatment.

\section{Conflict of Interest}

None declared.

\section{Ethical Approval}

This study was conducted with approval from the Local Ethical Committee.

\section{References}

[1] Marşan, G., Oztaş, E., Cura, N., Kuvat, S.V. and Emekli, U. (2010) Changes in Head Posture and Hyoid Bone Position in Turkish Class III Patients after Mandibular Setback Surgery. Journal of Cranio-Maxillo-Facial Surgery, 38, 113121. http://dx.doi.org/10.1016/j.jcms.2009.03.009

[2] Wolford, L.M. and Cottrell, D.A. (1996) Diagnosis of Macroglossia and Indications for Reduction Glossectomy. Ame- 
rican Journal of Orthodontics and Dentofacial Orthopedics, 110, 170-177. http://dx.doi.org/10.1016/S0889-5406(96)70105-1

[3] Miyawaki, S., Oya, S., Noguchi, H. and Takano-Yamamoto, T. (2000) Long-Term Changes in Dentoskeletal Pattern in a Case with Beckwith-Wiedemann Syndrome Following Tongue Reduction and Orthodontic Treatment. Angle Orthodontist, 70, 326-331.

[4] Vogel, J.E., Mulliken, J.B. and Kaban, L.B. (1986) Macroglossia: A Review of the Condition and a New Classification. Plastic and Reconstructive Surgery, 78, 715-723. http://dx.doi.org/10.1097/00006534-198678060-00001

[5] Ingervall, B. and Schmoker, R. (1990) Effect of Surgical Reduction of the Tongue on Oral Stereognosis, Oral Motor Ability, and the Rest Position of the Tongue and Mandible. American Journal of Orthodontics and Dentofacial Orthopedics, 97, 58-65. http://dx.doi.org/10.1016/S0889-5406(05)81710-X

[6] Swanson, L.T. and Murray, J.E. (1969) Partial Glossectomy to Stabilize Occlusion Following Surgical Correction of Prognathism. Report of a Case. Oral Surgery, Oral Medicine, Oral Pathology, Oral Radiology, and Endodontology, 27, 707-715. http://dx.doi.org/10.1016/0030-4220(69)90137-6

[7] Kawakami, S., Yokozeki, M., Takahashi, T., Horiuchi, S. and Moriyama, K. (2005) Siblings with Spaced Arches Treated with and without Partial Glossectomy. American Journal of Orthodontics and Dentofacial Orthopedics, 127, 364-373. http://dx.doi.org/10.1016/j.ajodo.2003.10.045

[8] Tanaka, O.M., Guariza-Filho, O., Carlini, J.L., Oliveira, D.D., Pithon, M.M. and Camargo, E.S. (2013) Glossectomy as an Adjunct to Correct an Open-Bite Malocclusion with Shortened Maxillary Central Incisor Roots. American Journal of Orthodontics and Dentofacial Orthopedics, 144, 130-140. http://dx.doi.org/10.1016/j.ajodo.2012.08.029

[9] Hotokezaka, H., Matsuo, T., Nakagawa, M., Mizuno, A. and Kobayashi, K. (2001) Severe Dental Open Bite Malocclusion with Tongue Reduction after Orthodontic Treatment. Angle Orthodontist, 71, 228-236.

[10] Medeiros, P.J., Camargo, E.S., Vitral, R. and Rocha, R. (2000) Orthodontic-Surgical Approach in a Case of Severe Open-Bite Associated with Functional Macroglossia. American Journal of Orthodontics and Dentofacial Orthopedics, 118, 347-351. http://dx.doi.org/10.1067/mod.2000.102390

[11] Schwenzer, N., Voy, E.D. and Niemczyk, H.M. (1977) Effect of Tongue Reduction on the Orthodontic and Surgical Treatment of Dysgnathia. Journal of Maxillofacial Surgery, 5, 15-20. http://dx.doi.org/10.1016/S0301-0503(77)80070-2 
Scientific Research Publishing (SCIRP) is one of the largest Open Access journal publishers. It is currently publishing more than 200 open access, online, peer-reviewed journals covering a wide range of academic disciplines. SCIRP serves the worldwide academic communities and contributes to the progress and application of science with its publication.

Other selected journals from SCIRP are listed as below. Submit your manuscript to us via either submit@scirp.org or Online Submission Portal.
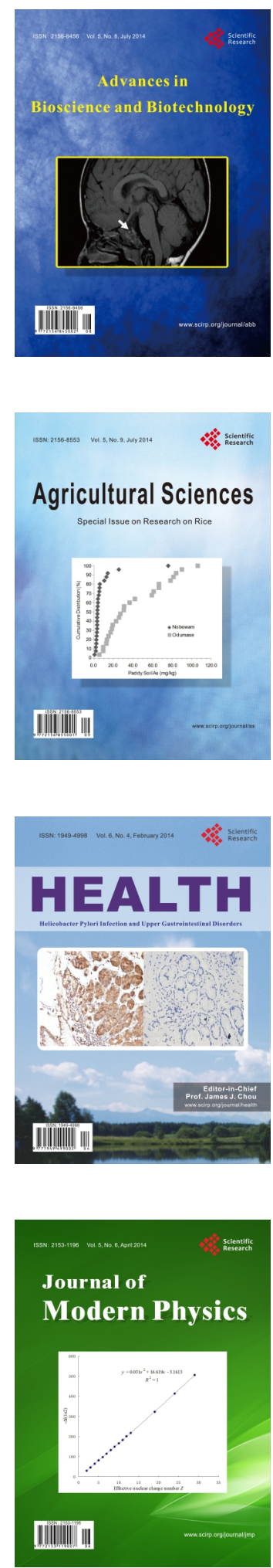
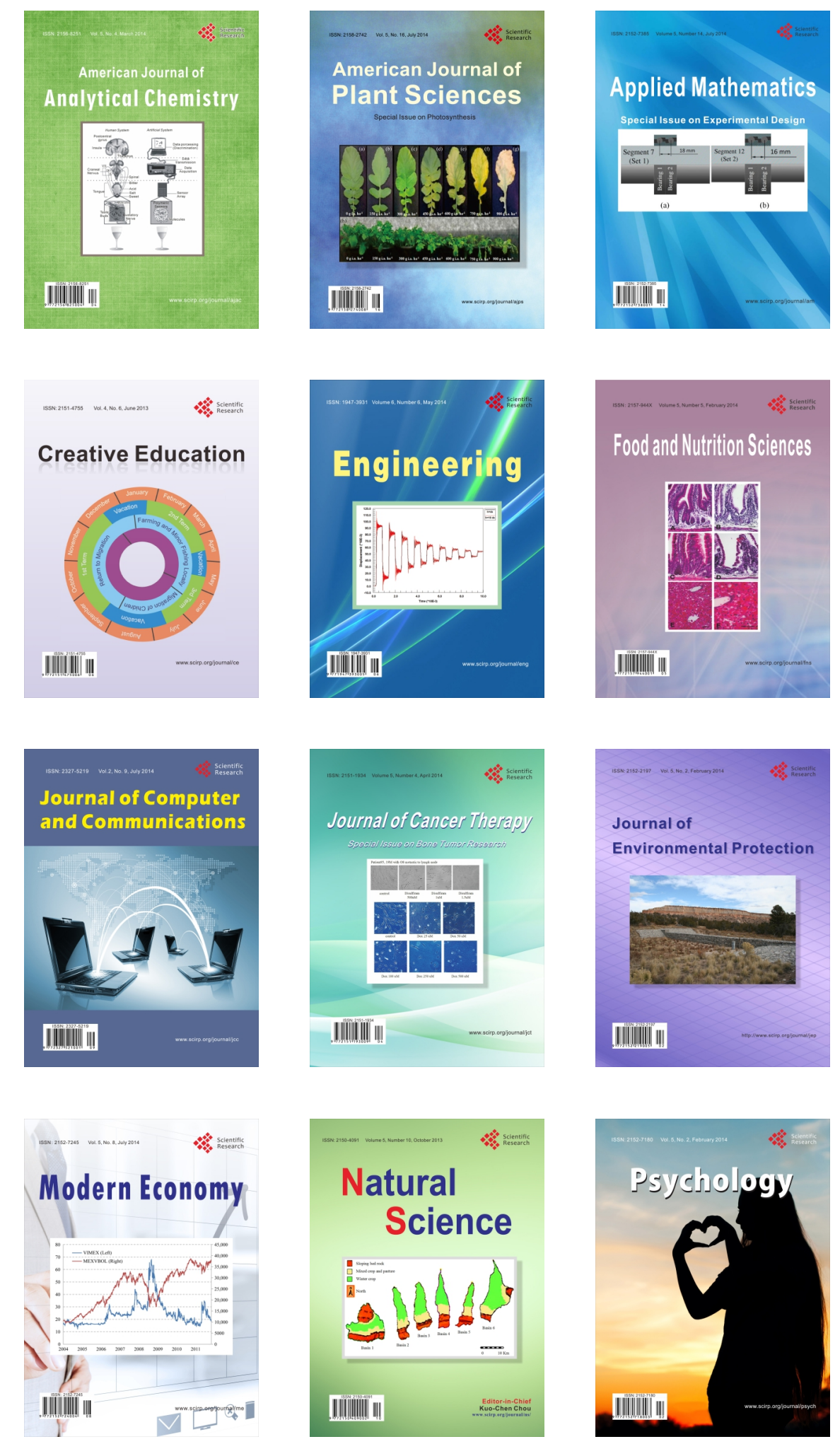